\title{
CONSERVATIVE APPROACH FOR MANAGEMENT OF POSTERIOR ATROPHIC MAXILLA USING IMPLANT ASSISTED OVERDENTURE (CLINCAL TRIAL)
}

\author{
Nayrouz A. Metwally ${ }^{1 *} B D S, M S c$, Ahmed M. Abdel-Hamid ${ }^{2} B D S, M S c, P h D$, Ahmed M. Hommos ${ }^{3}$ \\ $B D S, M S c, P h D$, Nermeen A. Rady ${ }^{4} B D S, M S c, P h D$
}

\begin{abstract}
INTRODUCTION: Implant assisted prostheses provide a higher degree of patient satisfaction than traditional prostheses. However, severe atrophy of the edentulous maxilla and maxillary sinus pneumatization may reduce the available bone in the posterior region for a safe and reliable implant-supported dental rehabilitation. Tilted implants in the anterior region of the maxilla were suggested to be useful in the treatment of posterior atrophic edentulous maxilla that allows the use of longer implants to gain more stability. This may preclude the use of conventional Implant overdenture abutments, requiring the use of divergence correcting attachments.

OBJECTIVES: The aim of the present study was to clinically evaluate the effect of the use of Smart Box accompanied with OT Equator attachment in retaining the inclined implant assisted overdenture for atrophic maxilla.

MATERIALS AND METHODS: Ten patients with posterior atrophic maxilla and partially dentate mandible with posterior occlusal stops were allocated for this study. For each patient, an implant assisted maxillary overdenture was fabricated using minimally invasive flapless surgical technique. Four implants were placed while the most anterior implants were axial and the most posterior implants divergent to 25 degrees using CAD/CAM surgical guide. The implants were loaded immediately by OT EQUATOR and smart box attachment retained maxillary overdenture. Each patient was evaluated clinically at the final prosthesis insertion (baseline), three, six and nine months post insertion. Modified gingival index (MGI), Clinical attachment Level (CAL) and Peri-implant probing depth (PIPD) are the clinical parameters that were evaluated.

RESULTS: MGI, CAL and PIPD revealed significant increase in both tilted and axial groups throughout the evaluation period intervals. Tilted implants group showed significantly greater increase in all parameters when compared with the axial group.

CONCLUSIONS: Within the limitations of this study, it can be concluded that combination of axial and tilted implant assisted overdenture is a predictable treatment option in case of severely atrophic posterior maxillae.

KEYWORDS: Implant overdenture, Tilted implants, Atrophic maxilla, OT Equator, Smart Box
\end{abstract}

1. Assistant lecturer, Removable Prosthodontics Department, Faculty of Dentistry, Alexandria University.

2. Professor of Prosthodontics, Faculty of Dentistry, Alexandria University.

3. Professor of Oral Medicine, Periodontology, Oral Diagnosis and radiology, Faculty of Dentistry, Alexandria University.

4. Lecturer of Prosthodontics, Faculty of Dentistry, Alexandria University.

*Corresponding author:

E-mail: nayrouz.metwally@alexu.edu.eg

\section{INTRODUCTION}

Atrophy or resorption of the alveolus is a continuous process that occurs once the teeth are lost (1). Complete denture (CD) is considered as the most traditional treatment option for edentulous arches and this is due to its low cost and wide accessibility. However, restoring the edentulous maxilla by $\mathrm{CD}$ when opposed with natural dentition is considered as a compromised rehabilitation biomechanically and functionally (2).

The rehabilitation of edentulous jaws with osseointegrated implants has been proven to be a predictable treatment over time (3). In comparison to the mandible, rehabilitation of a completely edentulous maxilla using osseointegrated implants is considered challenging procedure due to its tridimensional resorptive pattern resulting in insufficient bone volume for the ideal implant placement. The available bone is furthermore reduced by the pneumatization of maxillary sinus and this may render reliable implant-supported dental rehabilitation impossible (4).
Sinus floor elevation and guided bone regeneration have been reported during the last three decades with the aim of reconstructing the resorbed maxillae for more successful implant surgery. However, those procedures will add more time and cost to the implant rehabilitation procedure and also may expose to failure $(5,6)$.

Different therapeutic alternatives have been proposed in order to overcome such limitations, such as, short implants or implants placed in specific anatomical areas like the pterygoid region or the zygoma, but patient acceptance to these types of procedures could be low due to the invasive nature of the surgical procedure associated with an increased risk of morbidity and high costs $(7,8)$. Tilted implants were suggested in the treatment of atrophic edentulous maxilla to avoid the invasive bone augmentation procedures and the involvement of anatomical structures during surgery (9).

The combined use of axially placed and tilted implants represents another possible alternative for the treatment of atrophic edentulous maxilla, which has been extensively documented lately (10). 
The introduction of the maxillary implant overdenture (IOD) over the last two decades offered advantages over fixed implant restorations. This prosthetic design avoids the augmentation procedures required for fixed restorations (11). Moreover, it is more appropriate for patients requiring facial support (12). Furthermore, cleaning the implants restored with a fixed implant restoration in patients can be challenging (13).

Tilted implant placement may preclude the use of conventional IOD abutments, requiring the use of divergence correcting attachments (14). OT-Equator attachment is characterized by its low profile with the least overall dimension of any attachment system available. It is indicated to correct divergence up to $28^{\circ}$ between implants without affecting the functionality of the nylon cap (15).

Smart Box has been developed to be used with the OT Equator in cases of extreme divergences between the implants. It is provided with an inner tilting mechanism that enables a passive insertion with divergent implants up to $50^{\circ}(16)$.

The effect of attachment type on implants in maxillary arches depends on the functional forces specially when opposed by natural dentition in the anterior and premolar area. This research aimed to evaluate the use of tilted implant assisted overdenture with smart attachment in management of severely atrophic maxilla.

The null hypothesis is that the use of OT Equator with smart box attachment will have no effect on improvement clinically or radiographically of immediate inclined implant assisted overdenture for atrophic maxilla.

\section{MATERIALS AND METHODS}

\section{Informed consent}

A written informed consent was obtained from all patients who accepted to share in this study after explaining the procedures to them. It was also mentioned that the patient had the right of withdrawal from the study anytime without any consequences. Ethical approval for this study was obtained before beginning the study from the Research Ethics Committee, Faculty of Dentistry, Alexandria University, Egypt. All patients received appropriate dental care including removal of local factors, education and motivation to maintain proper oral hygiene

\section{Patient Selection Criteria:}

Ten male patients with age ranged from 30 to 65 years were selected in this study. Patients with completely edentulous maxilla, leaving less than $4 \mathrm{~mm}$ bone height posteriorly and sufficient amount of bone in the inter bicuspids region with opposing mandibular dentate or partially edentulous arch including bilateral posterior teeth. All patients in this study had adequate zone of keratinized mucosa. Patients of any systemic diseases and those who are unwilling to accept implant overdenture as a treatment modality were excluded from this study.

All patients who have participated in this study received maxillary $C D$ before the surgery and then four similarly designed 2-piece endosseous implants were placed in the interbicuspids region of maxillary arch. The implant system used in this study was Dentium Superline Fixtures (Dentium superline, Dentium Co. Ltd., Korea) and the implants were immediately loaded by implant assisted maxillary overdenture (IOD) retained by OTEquator (Ref.030, Rhein83, Rome, Italy) and Smart Box attachment (Ref.335SBC, Rhein83, Rome, Italy).
Dual scan procedure was used to fabricate a CAD/CAM surgical guide. Glass beads markers (SWARCO AG, Blattenwaldweg, A-6112 Watterns, Austria) were distributed randomly facially and palatally throughout the maxillary acrylic denture to select optimal implant sites. Scanning was done for both the patient wearing the denture and for the denture outside the patient mouth by the CBCT scanner (PaX I Insight, Vatech, Seoul, Korea). Three-dimensional implant planning software (OnDemand3D, Cybermed Inc., Seoul, Korea) allowed virtual planning for the location and angulation of the virtual implants that the two anterior implants were planned to be placed axially corresponding to the positions of the laterals with $8 \mathrm{~mm}$ length and $3.6 \mathrm{~mm}$ width. The two posterior implants were planned to be placed divergent to $25^{\circ}$ corresponding to the positions of the first premolars with 12-14 mm length and $3.6 \mathrm{~mm}$ width. Once the computer planning was accomplished, This plan was extracted as a "STL"' file, then a print-job was sent to the Printer's software (EnVisiontec Prefactory, EnVisiontec GMBH, Gladbeck, Germany) for the fabrication of the surgical guide. The 3D printer (EnVisionOne, EnVisiontec GMBH, Gladbeck, Germany) used the Stereolithographic technology to print the surgical guide using 3D printing resin (NextDent SG, NextDent, Soesterberg, Netherlands).

Prior to any treatment, Antibiotic therapy, Amoxicillin clavulanate $2 \mathrm{~g}$ (Augmentin manufactured by Medical Union Pharmaceuticals MUP, ARE) was prescribed to the patients an hour before treatment and $1 \mathrm{mg}$ twice daily during the following four days. All patients were instructed to use $0.12 \%$ Chlorhexidine mouthwash (Hexitol, ADCO; Egypt) one day before the surgery and continued for 2 weeks.

Surgical procedure was done under local anesthesia for all patients. Surgical template was fixed onto the ridge by the aid of fixation screws (Figure1). Osteotomies for the four implants were performed using the a universal surgical kit (In2Guide Universal Kit, Cybermed inc. USA). The OT Equator abutments were then screwed and tightened to $30 \mathrm{Ncm}$ with a torque wrench on the implant (Figure 2). The old maxillary CD of the patient was then relieved and refitted using silicon soft liner material (Promedica Dental Material Gmbh, USA). Every patient was instructed to complete the prescribed medication. Visits for the definitive prosthesis were scheduled for the next two weeks and the patient was instructed to use the old relined denture during this period.

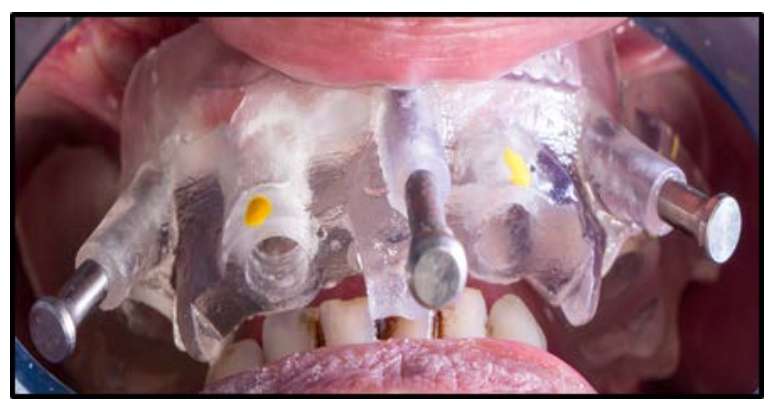

Figure (1): Digital surgical guide fixed using the fixation screws. 


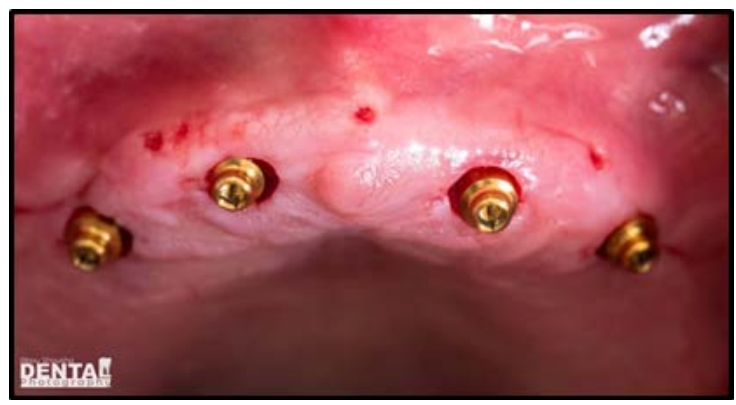

Figure (2): OT Equator abutments screwed and tightened.

A horse-shoe Maxillary IOD with metal framework was constructed. The maxillary denture was inserted inside the patient's mouth to check the fit of the denture base to the attachments using a pressure indicating paste (Mizzy, Keystone industries GmbH, Singen, USA). Block-out spacers were placed over the head of each OT Equator abutments (Figure 3) and then metal sockets with (black processing caps) were snapped on. The areas over the housings were relieved with an acrylic bur until the denture can be fully seated passively in the patient's mouth, A mix of autopolymerized acrylic resin "pick-up material" was made, and the spaces were filled using a plastic filling instrument. The denture was inserted into position in the oral cavity. The patient was gently guided into centric occlusion and left for 4 minutes to allow for polymerization to occur. the denture was removed and the spacers were discarded. The OT Equator core tool was used for the procedure of removing the black processing caps from the socket and replacing it with the final nylon caps replacement (Clear Colored Caps) which provide standard retention $1300 \mathrm{gf}$ retention force (Figure 3).

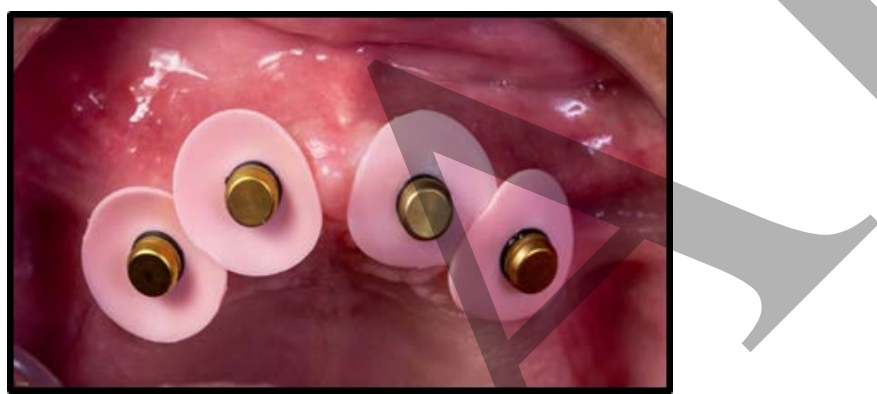

Figure (3): Plastic spacers and metal sockets was snapped on OT Equator

The following clinical periodontal parameters of the implant abutments were evaluated for every patient at the time of final prosthesis insertion (baseline), three, six and nine months after insertion (Fig 4): Modified gingival index (MGI) The peri-implant mucosal tissues around the implants were assessed using the modified, non-invasive (no probing) technique called Löe and Silness index (17), Clinical Attachment level (CAL) which is the distance from the junction implant/abutment to the most apically probable portion in millimeters (18). In this study the top of the OT Equator abutment was used as a fixed "reference point" instead of implant/crown junction and Peri-implant probing depth (PIPD) (19) by measuring the distance between the gingival margin and the most apically probable portion in millimeters $(\mathrm{mm})$ using a graduated plastic periodontal probe (Helmut ZEPF, Medizintechik GMBH, Germany).

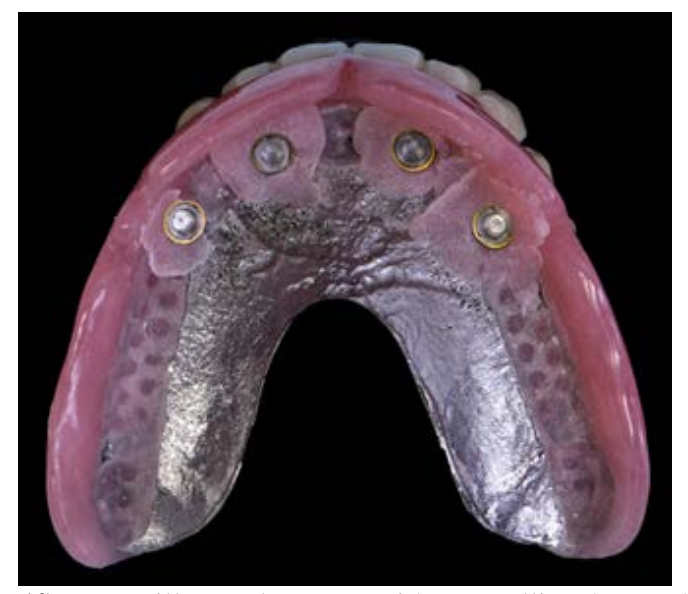

Figure (4): Maxillary denture with metallic horse-shoe framework and housings in place.

Those indices were assessed at four sites around each implant, the sum of each score was calculated from all these surfaces and then divided by 4 to obtain the score for each implant. Indices of the two axial implants were added to each other, and then divided by 2 to get the mean for each case. The same was done for the other two tilted implants.

\section{Statistical Analysis:}

Data were fed to the computer and analyzed using IBM SPSS software package version 20.0. (Armonk, NY: IBM Corp) (20). The Kolmogorov-Smirnov test was used to verify the normality of distribution. Quantitative data were described using range (minimum and maximum), mean, standard deviation and median. Significance of the obtained results was judged at the $5 \%$ level. The used tests were ANOVA with repeated measures for normally distributed quantitative variables, to compare between more than two periods or stages, and Post Hoc test (Bonferroni adjusted) for pairwise comparisons, Wilcoxon signed ranks test for abnormally distributed quantitative variables, to compare between two periods and Friedman test for abnormally distributed quantitative variables, to compare between more than two periods or stages and Post Hoc Test (Dunn's) for pairwise comparisons.

\section{RESULTS}

The peri-implant areas were evaluated clinically at the time of final prosthesis insertion (base line), three, six and nine months after insertion of the prosthesis. Data were collected, tabulated, and statistically presented as follows.

\section{A. Modified Gingival Index (MGI)}

There was an increase in the mean and standard deviation values of MGI in both groups throughout the different periods of follow up. This increase was only statistically insignificant when comparing between the baseline and 3 months in both groups. The comparison between the two groups, the mean values of MGI in group II were significantly greater than that in group I throughout the three periods as shown in Table (1). 
Figure (1): Comparison between the two studied groups regarding MGI at different periods of follow up.

\begin{tabular}{|c|c|c|c|c|c|}
\hline $\begin{array}{c}\text { Modified } \\
\text { gingival } \\
\text { index }\end{array}$ & Baseline & $\begin{array}{c}3 \\
\text { Months }\end{array}$ & $\begin{array}{c}6 \\
\text { Months }\end{array}$ & $\begin{array}{c}9 \\
\text { Months }\end{array}$ & $\mathbf{p}$ \\
\hline $\begin{array}{l}\text { Group I } \\
\text { (Axial) }\end{array}$ & & & & & \\
\hline Min. - Max & & & $\begin{array}{c}0.89- \\
1.82\end{array}$ & $\begin{array}{c}1.15- \\
1.38\end{array}$ & $50001^{*}$ \\
\hline Median (IQR) & $\begin{array}{c}0.13(0.0- \\
0.16)\end{array}$ & $\begin{array}{c}0.13(0.0 \\
-0.25)\end{array}$ & $\begin{array}{l}1.06(0.9 \\
7-1.82) \\
\end{array}$ & $\begin{array}{c}1.38(1.32 \\
-1.38)\end{array}$ & $<.001$ \\
\hline $\mathbf{p}_{\text {Baseline }}$ & & 0.862 & $0.001^{*}$ & $<0.001^{*}$ & \\
\hline $\begin{array}{l}\text { Sig. bet. } \\
\text { Periods }\end{array}$ & & \multicolumn{3}{|c|}{$\mathrm{p}_{1}=0.002^{*}, \mathrm{p}_{2}=0.488$} & \\
\hline $\begin{array}{l}\text { Group II } \\
\text { (Tilted) }\end{array}$ & & & & & \multirow{3}{*}{$<0.001^{*}$} \\
\hline Min. - Max. & $0.0-0.25$ & $\begin{array}{l}0.25- \\
0.37\end{array}$ & $\begin{array}{l}1.25- \\
1.60\end{array}$ & $1.25-2.0$ & \\
\hline Median (IQR) & $\begin{array}{c}0.06(0.0- \\
0.25)\end{array}$ & $\begin{array}{c}0.25(0.2 \\
5-0.37)\end{array}$ & $\begin{array}{l}1.44(1.2 \\
5-1.60)\end{array}$ & $\begin{array}{c}1.98(1.25 \\
-2.0)\end{array}$ & \\
\hline $\mathbf{p}_{\text {Baseline }}$ & & 0.083 & $<0.001^{*}$ & $<0.001^{*}$ & \\
\hline $\begin{array}{l}\text { Sig. bet. } \\
\text { periods }\end{array}$ & & \multicolumn{3}{|c|}{$\mathrm{p}_{1}=0.046^{*}, \mathrm{p}_{2}=0.225$} & \\
\hline $\mathrm{Z}\left(\mathbf{p}_{0}\right)$ & $(0.705)$ & $\left(0.005^{*}\right)$ & $\left(0.026^{*}\right)$ & $\left(0.026^{*}\right)$ & \\
\hline
\end{tabular}

$\mathrm{F}: \mathrm{F}$ test (ANOVA)

$\mathrm{P}: \mathrm{P}$ value for ANOVA test

Sig. bet. periods was done using Post Hoc Test (Dunn's) for ANOVA

pBaseline: $p$ value for comparing between Baseline and each other periods

p1: $p$ value for comparing between 3 Months and 6 Months p2: p value for comparing between 6 Months and 9 Months $\mathrm{Z}, \mathrm{p} 0$ : $\mathrm{t}$ and $\mathrm{p}$ values for Wilcoxon signed ranks test for comparing between Axial and Tilted

*: statistically significant at $\mathrm{p} \leq 0.05$

\section{B. Clinical Attachment Level (CAL)}

There was a statistically significant increase in the mean and standard deviation values of CAL in both groups throughout the different periods of follow up. The comparison between the two groups showed that, the mean values of CAL in group II were significantly greater than that in group I throughout the evaluation periods as shown in Table (2).

Table (2): Comparison between the two studied groups regarding percent of change in CAL at different periods of follow up.

\begin{tabular}{|c|c|c|c|c|c|}
\hline $\begin{array}{c}\text { Clinical } \\
\text { Attachment } \\
\text { level }\end{array}$ & Baseline & 3 Months & 6 Months & 9 Months & $\mathbf{P}$ \\
\hline \multicolumn{6}{|l|}{$\begin{array}{l}\begin{array}{l}\text { Group I } \\
\text { (Axial) }\end{array} \\
\end{array}$} \\
\hline Min. - Max. & $3.15-3.22$ & $3.34-3.42$ & $3.44-3.53$ & $3.44-3.60$ & \multirow[t]{2}{*}{$<0.001^{*}$} \\
\hline Mean \pm SD & $3.20 \pm 0.03$ & $3.38 \pm 0.04$ & $3.50 \pm 0.04$ & $3.54 \pm 0.07$ & \\
\hline $\mathbf{p}_{\text {Baseline }}$ & & $<0.001^{*}$ & $<0.001^{*}$ & $<0.001^{*}$ & \\
\hline $\begin{array}{l}\text { Sig. bet. } \\
\text { Periods }\end{array}$ & & \multicolumn{3}{|c|}{$\mathrm{p}_{1}<0.001^{*}, \mathrm{p}_{2}=0.075$} & \\
\hline $\begin{array}{l}\text { Group II } \\
\text { (Tilted) }\end{array}$ & & & & & \multirow{4}{*}{$0.023^{*}$} \\
\hline Min. - Max. & $1.29-3.53$ & $3.59-3.68$ & 3.71-3.85 & 3.75-3.92 & \\
\hline Mean \pm SD. & $3.0 \pm 0.91$ & $3.64 \pm 0.04$ & $3.78 \pm 0.05$ & $3.82 \pm 0.06$ & \\
\hline $\mathbf{p}_{\text {Baseline }}$ & & 0.307 & 0.120 & 0.096 & \\
\hline $\begin{array}{l}\text { Sig. bet. } \\
\text { periods }\end{array}$ & & \multicolumn{3}{|c|}{$\mathrm{p}_{1}<0.001^{*}, \mathrm{p}_{2}=0.012^{*}$} & \\
\hline$\left(\mathbf{p}_{0}\right)$ & $(0.500)$ & $\left(<0.001^{*}\right)$ & $\left(<0.001^{*}\right)$ & $\left(<0.001^{*}\right)$ & \\
\hline
\end{tabular}

F: F test (ANOVA)

$P$ : P value for ANOVA test
Sig. bet. periods was done using Post Hoc Test (Bonferroni) for ANOVA

pBaseline: $p$ value for comparing between Baseline and each other periods

$\mathrm{p}_{1}$ : $\mathrm{p}$ value for comparing between 3 Months and 6 Months p2: p value for comparing between 6 Months and 9 Months

po: $\mathrm{p}$ values for Paired t-test for comparing between Axial and Tilted

*: statistically significant at $\mathrm{p} \leq 0.05$

\section{Peri-Implant Probing Depth (PIPD)}

The results of this study showed that there was a statistically significant increase in the mean and standard deviation values of PIPD in group I (Axial implants) and group II (Tilted implants) throughout the different periods of follow up. The mean values of PIPD in group II were significantly greater than that in group I throughout the three periods as shown in Table (3).

Table (3): Comparison between the two studied groups regarding PIPD at different periods of follow up.

\begin{tabular}{|c|c|c|c|c|c|}
\hline $\begin{array}{c}\text { Peri-implant } \\
\text { probing } \\
\text { depth }\end{array}$ & Baseline & 3 Months & 6 Months & 9 Months & $\mathbf{p}$ \\
\hline $\begin{array}{l}\text { Group I } \\
\text { (Axial) } \\
\text { Min. - Max. } \\
\text { Mean } \pm \text { SD. } \\
\end{array}$ & $\begin{array}{l}1.15-1.22 \\
1.20 \pm 0.03 \\
\end{array}$ & $\begin{array}{l}1.34-1.42 \\
1.38 \pm 0.04 \\
\end{array}$ & $\begin{array}{l}1.44-1.53 \\
1.50 \pm 0.04 \\
\end{array}$ & $\begin{array}{l}1.44-1.60 \\
1.54 \pm 0.07 \\
\end{array}$ & $\begin{array}{c}<0.00 \\
1^{*} \\
\end{array}$ \\
\hline Paseline & & $<0.001^{*}$ & $<0.001^{*}$ & $<0.001^{*}$ & \\
\hline $\begin{array}{l}\text { Sig. bet. } \\
\text { Periods }\end{array}$ & & \multicolumn{3}{|c|}{$\mathrm{p}_{1}<0.001^{*}, \mathrm{p}_{2}=0.075$} & \\
\hline $\begin{array}{l}\text { Group II } \\
\text { (Tilted) } \\
\text { Min. - Max. } \\
\text { Mean } \pm \text { SD. }\end{array}$ & $\begin{array}{l}1.28-1.53 \\
1.40 \pm 0.13\end{array}$ & $\begin{array}{l}1.59-1.68 \\
1.64 \pm 0.04\end{array}$ & $\begin{array}{l}1.71-1.85 \\
1.78 \pm 0.05 \\
\end{array}$ & $\begin{array}{l}1.75-1.92 \\
1.82 \pm 0.06\end{array}$ & $\begin{array}{c}<0.00 \\
1^{*} \\
\end{array}$ \\
\hline Paseline & & $<0.001^{*}$ & $<0.001^{*}$ & $<0.001^{*}$ & \\
\hline $\begin{array}{l}\text { Sig. bet. } \\
\text { periods }\end{array}$ & & \multicolumn{3}{|c|}{$\mathrm{p}_{1}<0.001^{*}, \mathrm{p}_{2}=0.012^{*}$} & \\
\hline$\left(\mathrm{p}_{0}\right)$ & $\left(<0.001^{*}\right)$ & $\left(<0.001^{*}\right)$ & $\left(<0.001^{*}\right)$ & $\left(<0.001^{*}\right)$ & \\
\hline
\end{tabular}

$\mathrm{P}$ : P value for ANOVA test

Sig. bet. periods was done using Post Hoc Test (Bonferroni) for ANOVA

pBaseline: p value for comparing between Baseline and each other periods

$\mathrm{p}_{1}$ : $\mathrm{p}$ value for comparing between 3 Months and 6 Months $\mathrm{p}_{2}$ : $\mathrm{p}$ value for comparing between 6 Months and 9 Months $\mathrm{p}_{0}: \mathrm{p}$ values for Paired t-test for comparing between Axial and Tilted

*: statistically significant at $\mathrm{p} \leq 0.05$

\section{DISCUSSION}

Lack of stability and insufficient retention are problems that edentulous patients often report. Implant overdenture is a treatment modality offers a significant increase in retention and stability over conventional complete denture, providing a considerable improvement in quality of life $(21,22)$.

An important aspect in the rehabilitation of maxillary edentulous patients with endosseous implants is the fact that in many cases there is sufficient alveolar crest volume in the anterior region, while in the premolar and molar regions, severe bone resorption is present $(23,24)$. Tilted implants were suggested to be useful in the treatment of severely resorbed maxilla, avoiding the bone augmentation procedures and the involvement of anatomical structures during surgery (25). 
In this study ten patients were selected with their age ranging from 35 to 65 years. Older patients were not chosen as success rates might be less than optimal with advancing age, although endosseous implants were not contraindicated in the elderly (26). Moreover, the patients were free from any intra-oral or systemic diseases that could complicate or alter the implant treatment design (27). The presence of adequate amount of keratinized mucosa was important, as a negative correlation was found between keratinized mucosa width and mucosal recession; a wider mucosal band was associated with less mucosal recession (28).

An overdenture supported by two to four implants is often presented as a "low cost" implant treatment alternative because it uses fewer implants and components than a full-arch implant-supported fixed prosthesis (29). Sadowsky SJ et al (23) evaluated maxillary implant overdentures with emphasis on number of implants and anchorage design. He concluded that a number of 4 implants was the minimum to support a maxillary overdenture. Many reports have shown good outcomes with the use of only four implants, two axial and two tilted $(30,31)$.

Concerning the implant design which has a greater impact on the functional surface area, Superline Dentium implant was used in this study. It had tapered body design of providing initial stability and bone expansion response for reliable and easy installation. The interface between abutment and fixture was mediated via a conical seal design that distributes the load to the surrounding cortical bone evenly and prevents screw loosening. The implants had a micro thread configuration in the cervical portion, with SLA (Sandblasting with Large grit and Acid etching) surface (32).

The reasons to choose the flapless technique are to avoid the disadvantage of the flap technique including alteration in the vascularization of the bone periosteum which affect the remodeling processes around the implant after flap reflection (33). Other advantages of the flapless implant surgery include less traumatic surgery, decreased operative time, rapid postsurgical healing, fewer postoperative complications and increased patient comfort (34).

CAD/CAM-based surgical guides were chosen as they offer many advantages, The virtual 3- dimensional views of the bony morphology allow the surgeon to yisualize the surgical bone site prior to implant placement; risks such as inadequate osseous support or compromise of important anatomic structures are avoided; incorporation of prosthetic planning, allows the treatment to be optimized from a prosthodontics and biomechanical point of view specially in case of tilted implants with certain angulation as in the current study (35).

The solitary attachments for maxillary overdentures provide an acceptable implant prognosis. Slot W et al (36) stated a survival rate of $96.3 \%$ for 4 implants with bar anchor and $95.2 \%$ for solitary 4 implants with ball anchor. Cavallaro JS Jr and Tarnow DP (37) documented a 100\% success with maxillary overdentures supported on 4 solitary implants. Eccellente $\mathrm{T}$ et al (38) demonstrated high success rates of solitary attachments even after immediate loading protocols. These data indicate that solitary attachments for maxillary overdentures provide an acceptable implant prognosis.
The overdentures had a horseshoe design and were reinforced by a cast-metal framework. The reduction or elimination of palatal coverage, with maxillary implantsupported overdentures may be perceived as advantageous to patients by providing greater comfort through reduction of tissue coverage for complete denture wearer (39).

Rhein83; which produces attachments for removable prosthesis, the OT EQUATOR is characterized by its low profile. The system employs a reduced vertical profile of $2.1 \mathrm{~mm}$ with a $4.4 \mathrm{~mm}$ diameter. Rhein83 also has developed Smart Box, which can be used with the OT Equator in cases of extreme divergencies between the implants. The Smart Box has an inner tilting mechanism that enables a passive insertion with divergent implants up to 50 degrees (16).

Immediate loading protocol was adopted in this study. The rationale of immediate loading was to shorten the time frame for both surgery and prosthesis insertion. It should therefore translate into faster achievement of the masticatory function without affecting the success rate that have been reported for endosseous dental implants. A comprehensive review of clinical trials has concluded that many reports demonstrated that immediately/early loading of dental implants with a maxillary overdenture is a predictable treatment approach and results in a favorable implant/prosthesis survival, soft tissue health and patient satisfaction outcomes $(40,41)$.

Regarding the Modified Gingival Index (MGI), values were increased along the different periods of follow up in both groups; this may be attributed to the resiliency of the OT equator attachment, which allows denture movements and accumulation of plaque under the denture. This was also in accordance with Naema A et al (42) and Marrone A et al (43) who found that, implants covered with overdentures were more associated with peri-mucositis.

Also, there was an statistically significant increase in the CAL in both groups. The results demonstrated that the attachment loss was in the range of 0.03- $0.07 \mathrm{~mm}$ during the entire period of this study. These results were in agreement with Joseph D et al. (44) who found that, during the first year of function an average attachment loss of 0.4 $\mathrm{mm}$ was observed. And this is close to the mean annual attachment loss found by Schatzle M et al (45).

Periodontal parameters have commonly been used for clinical monitoring of the soft tissues around dental implants (46). The mean PIPD in the present study showed significant increase throughout all interval times of the study period in both groups. However, these results were less than $2 \mathrm{~mm}$ during the entire period of follow up. This was in agreement with the studies of Neiva RF et al (47), Buser D et al (48) and Salvi GE et al (49) who have indicated that successful implants allow probe penetration of approximately $3 \mathrm{~mm}$ probing depth. The increased PD could be related to increased peri-implant vertical bone resorption with time and peri-implant soft tissue enlargement.

When the two groups were compared, The mean values of (PIPD), (CAL) and (MGI) in group II (Tilted implants) were significantly greater than that in group I (Axial implants) throughout the three periods. However, the PIPD and CAL results are still within the interval of records indicating successful implants (42-45). 
Those findings were in line with a systematic review by Wei-Shao Lin et al (50) which concluded that with the intentionally titled implant being located in the posterior portion of the jaw, these implants are subjected to higher occlusal force than the anterior implants. That is why it would not be surprising to see some effect on implant performance when subjected to immediate loading.

The results of this study were in contrary to the observation of a study by Degidi $M$ et al (51) which reported greater probing depths and bleeding on probing of tilted implants when compared with axial implants. However, this increase in readings were insignificant and this might be attributed to the use of 6 implants instead of 4 used in the current study.

Moreover, The results of this study showed disagreement with a five year clinical study conducted by Agini A et al (52) evaluating tilted versus axial implant immediately loaded implants by implant-supported fixed restorations and observed no significant difference between axial or tilted implants after the first year of loading

The physiologic depth of peri-implant sulcus of successfully osseointegrated implants has been a matter of debate because the magnitude of probe penetration into the peri-implant pocket depends on many factors including the probing force applied, firmness of marginal tissues, diameter of the probe tip, and roughness of implant (44).

\section{CONCLUSION}

Within the limitations of this study regarding the sample size and short study periods; it can be concluded that the combination between axial and tilted implant assisted overdenture may be recognized as a predictable and successful treatment option for severely atrophic posterior maxilla. The clinical results of this study indicated that implant tilting seems to be both clinically advantageous and can be well justified from a biomechanical point of view.

\section{CONFLICT OF INTEREST}

The authors declare that they have no conflicts of interest.

\section{ACKNOWLEDGMENTS}

I would like to thank Dr. Nermeen Rady and Ahmed Mobarak for their continuous support during conduction of this study.

\section{REFERENCES}

1-Felton DA. Edentulism and comorbid factors. J Prosthodont. 2009;18(2):88-96.

2-Bhandari S. Outcome of single maxillary complete dentures opposing mandibular teeth: A need to introspect on the prosthodontic treatment protocol. J Indian Prosthodont Soc. 2016;16(1):15-9.

3-Adell R, Eriksson B, Lekholm U, Branemark P, Jemt T. Long-term follow-up study of osseointegrated implants in the treatment of totally edentulous jaws. Int $\mathrm{J}$ Oral Maxillofac Implants. 1990;5: 347-59.

4-Chiapasco M, Brusati R, Ronchi P. LeFort I osteotomy with interpositional bone grafts and delayed oral implants for the rehabilitation of extremely atrophied maxillae: A 1 -9- year clinical follow-up study on humans. Clin Oral Implants Res.2007:18:74-85.
5-Wallace S, Froum SJ. Effect of maxillary sinus augmentation on the survival of endosseous dental implants as compared to the survival of implants placed in the nongrafted posterior maxilla: an evidence-based literature review. Ann Periodontol. 2003;8:328-43.

6-Del Fabbro M, Testori T, Francetti L, Weinstein R. Systematic review of survival rates for implants placed in grafted maxillary sinus. Int J Periodontics Restorative Dent. 2004;24:565-77.

7-Bahat O. Osseointegrated implants in the maxillary tuberosity: report on 45 consecutive patients. Int J Oral Maxillofac Implants. 1992; 7: 459-67.

8-Branemark PI, Grondahl K, Ohrnell LO, Nilsson P, Petruson B, Svensson B et al. Zygoma fixture in the management of advanced atrophy of the maxilla: technique and long-term results. Scand J Plast Reconstr Surg Hand Surg. 2004; 38: 70-85.

9-Krekmanov L, Kahn M, Rangert B, Lindstrom H. Tilting of posterior mandibular and maxillary implants for improved prosthesis support. Int $\mathrm{J}$ Oral Maxillofac Implants. 2000;15(3):405-14.

10-Soto-Penaloza D, Zaragozí-Alonso R, Penarrocha-Diago M, Penarrocha-Diago M. The all-on-four treatment concept: Systematic review. Journal of Clinical and Experimental Dentistry. 2017;9(3):474-88.

11-Hof M, Tepper G, Semo B, et al. Patients’ perspectives on dental implant and bone graft surgery: Questionnairebased interview survey. Clin Oral Implants Res 2014;25:42-45.

12-Kronström M, Widbom C, Soderfeldt B. Patient evaluation with maxillary implant-supported overdentures. Clin Oral Implants Res 2006;8:39-43.

13-Zitzmann NU, Marinello CP. Treatment plan for restoring the edentulous maxilla with implant-supported restorations: Removable overdenture versus fixed partial denture design. J Prosthet Dent 1999;82:188-196.

14-Evtimovska E, Masri R, Driscoll CF, Romberge V.The Change in Retentive Values of Locator Attachments and Hader Clips over Time. I J Prosthodont 2009;18:479-83.

15-Rizk F. Comparative study of OT-Equator profile attachment versus GPS attachment in implant retained mandibular overdenture case. Egypt Dent J. 2012,58(1):65-9.

16-Rhein83 USA Product Catalog 2015-2016.

17-Silness J, Löe H. Periodontal disease in pregnancy. II. Correlation between oral hygiene and periodontal condition. Acta Odontol Scand 1964; 22:121-35.

18-Mombelli A, Van Oosten MA, Schurch E, Land NP. The microbiota associated with successful or failing osseointegrated titanium implants. Oral Microbiol Immunol. 1987; 2:145-51.

19-Brägger U, Bürgin WB, Hämmerle CH, Lang NP. Associations between clinical parameters assessed around implants and teeth. Clin Oral Implants Res 1997; 8:412-21.

20-Kirkpatrick LA, Feeney BC. A simple guide to IBM SPSS statistics for version 20.0. Student ed. Belmont, Calif.: Wadsworth, Cengage Learning; 2013.

21-Takanashi y, Penrod JR, Lund JP, et al. A cost comparison of mandibular two-implant overdenture and conventional denture treatment. Int J Prosthodont. 2004; 17:181-186.

22-Heydecke G, Thomason JM, Awad MA, et al. Do mandibular implant overdentures and conventional complete dentures meet the expectations of edentulous patients? Quintessence Int. 2008;39:803-809. 
23-Sadowsky SJ. Treatment considerations for maxillary implant overdentures: a systematic review. J Prosthet Dent. 2007 Jun;97(6):340-8.

24-Morand M, Irinakis T. The challenge of implant therapy in the posterior maxilla: providing a rationale for the use of short implants. J Oral Implantol. 2007;33:257-66.

25-Albrektsson T, Brånemark P-I, Eriksson A, Lindstrom J. The preformed autologous bone graft. Scand J Plast Reconstr Surg 1978;12:215-223.

26-Baig MR, Rajan M. Effects of smoking on the outcome of implant treatment: a literature review. Indian J Dent Res 2007; 18: 190-5.

27-Scully C, Hobkirk J, Dios PD. Dental endosseous implants in the medically compromised patient. J Oral Rehabil 2007; 34: 590-9

28-Chung DM, Oh TJ, Shotwell JL, et al. Significance of keratinized mucosa in maintenance of dental implants with different surfaces. J Periodontol. 2006; 77(8):1410-1420.

29-DarioLJ. A maxillary implant overdenture that utilizes angle- correcting abutments. J Prosthodont 2002;11:41-45.

30-Malo P, Rangert B, Nobre M. All-on-4 immediate-function concept with Branemark system implants for completely edentulous maxillae: a 1-year retrospective clinical study. Clin Implant Dent Relat Res 2005; 7 (1):88-94.

31-Weinstein R, Agliardi E, Fabbro MD, Romeo D, Francetti L. Immediate rehabilitation of the extremely atrophic mandible with fixed full-prosthesis supported by four implants. Clin Implant Dent Relat Res 2012; 14:434-441.

32-Lee JY, Park HJ, Kim JE, Choi YG, Kim YS, Huh JB et al. A 5-year retrospective clinical study of the Dentium implants. J Adv Prosthodont. 2011 Dec; 3: 229-35.

33-Arisan V, Karabuda CZ, Ozdemir T (2010) Implant surgery using bone- and mucosa-supported stereolithographic guides in totally edentulous jaws: surgical and post-operative outcomes of computer-aided vs. standard techniques. Clin Oral Implants Res 21: 980 988.

34-Sunitha RV, Sapthagiri E (2013) Flapless implant surgery: a 2-year follow-up study of 40 implants. Oral Surg Oral Med Oral Pathol Oral Radiol 116: e237-e243

35-Holst S, Blatz MB, Eitner S. Precision for computerguided implant placement: using 3D planning software and fixed intraoral reference points. J Oral Maxillofac Surg. 2007;65:393-399.

36-Slot W, Raghoebar GM, Vissink A, Huddleston Sla ter JJ, Meijer HJA. A systematic review of implant-supported maxillary overdentures after a mean observation period of at least 1 year. J Clin Periodontol 2010; 37:98-110

37-Cavallaro JS Jr, Tarnow DP. Unsplinted implants retaining maxillary overdentures with partial palatal coverage: report of 5 consecutive cases. Int $\mathrm{J}$ oral Maxillofac Implants. 2007;22:808-814.

38-Eccellente T, Piombino M, Piattelli A, et al. Immediate loading of dental implants in the edentulous maxilla. Quintessence Int. 2011;42:281-289.
39-Jour E, Fadl E, AbdelFattah. Comparative Study of Two Designs of Maxillary Implant-Supported Overdentures. Egy dent J 2009;55(2):1845-56.

40-Ghoul WE, Chidiac JJ . Prosthetic Requirements for Immediate Implant Loading: A Review. J Prosthodont 2012; 21(2):141-54.

41-AlFadda S. Early and immediate loading protocols for overdentures in completely edentulous maxillae: A comprehensive review in the clinical trials. The journal of contemporary dental practice.2014;15(6):797-805.

42-Naema A, Nabila M , Ahmed A. Clinical Evaluation of the Implant Retained Overdenture with OT-Equator Attachments. IJSR 2016;5(9): 643-7.

43-Marrone A, Lasserre J, Bercy P, Brecx MC. Prevalence and risk factors for peri-implant disease in Belgian adults. Clin Oral Implants Res . 2013;24(8):934-40.

44-Joseph D, Gallina S, Paoli N, Miller N, Penaud J, Ambrosini P. A retrospective clinical study of implantretained prosthetic partial dentures: A follow up investigation. J of Dent Implants. 2014;4(1):38-43.

45-Schätzle M, LÖE H, Lang NP, H Heinz-Mayfield LJ, BüRGIN W, Anerud A et al. Clinical course of chronic periodontitis. III. Patterns, variations and risks of attachment loss. J of clin implant ; 2003;30(10): 9-18.

46-Myshin HL, Wiens JP. Factors affecting soft tissue around dental implants: a review of the literature. J Prosthet Dent. 2005;94(5):440-4.

47-Neiva RF, Neiva KG, Oh TJ, Wang HL. Clinical and morphological aspects of the implant/soft tissue interface. Int Chin J Dent, 2, pp. 151-61, 2002.

48-Buser D, Weber HP, Lang NP. Tissue integration of nonsubmerged implants. l-year results of a prospective study with 100 ITI hollow- cylinder and hollow-screw implants. Clin Oral Implants Res . 1990;1(1):33-40.

49-Salvi GE, Lang NP. Diagnostic parameters for monitoring peri-implant conditions. Int $\mathrm{J}$ oral Maxillofac Implants. 2004;19(7) 56-66

50-Wei-Shao Lin, Steven E. Eckert .Clinical performance of intentionally tilted implants versus axially positioned implants: A systematic review. Clin Oral Impl Res. 2018;29(16):78-105.

51-Degidi M, Nardi d, Piattelli A. Immediate Loading of the Edentulous Maxilla with a Definitive Restoration Supported by an Intraorally Welded Titanium Bar and Tilted Implants. Int $\mathrm{J}$ Oral Maxillofac Implants. 2010;6(25):1175-82

52-Agnini A, Agnini A M, Romeo D, Chiesi M, Chiesi L, Stappert FJ. Clinical Investigation on Axial versus Tilted Implants for Immediate Fixed Rehabilitation of Edentulous Arches: Preliminary Results of a Single Cohort Study. Clin Implant Dent Relat Res 2014 ;16(4): 52-39 